\title{
STABILISASI TANAH LEMPUNG KABUPATEN SORONG DENGAN KAPUR SEBAGAI LAPISAN SUB - GRADE JALAN ( Studi Kasus Daerah Mariat Pantai )
}

\author{
Ahmad Ibnu Asfian \\ Program Studi Teknik Sipil Universitas Muhammadiyah Sorong \\ Jl. Pendidikan No. 27, Kota Sorong 98400 \\ Email : tekniksipilsorong@gmail.com
}

\begin{abstract}
ABSTRAK
Daerah Mariat Pantai adalah salah satu kecamatan di Kabupaten Sorong. Kondisi jalan di daerah tersebut sangat rusak parah sepanjang jalan sekitar 1,5 Km sejak tahun 2014 yang lalu. Tujuan penelitian ini ditekankan pada bagaimana mengetahui kelayakan tanah yang distabilkan dengan kapur sebagai lapisan pondasi bawah pada suatu perkerasan jalan. Penstabilan tanah menggunakan kapur sebagai lapisan perkerasan dimaksudkan sebagai campuran lapisan perkerasan tanah. Adapun model pola pengujian menggunakan uji CBR Unsoaked, sempel langsung di uji untuk mengetahui daya dukung tanah tersebut. Pengujian tanah asli yang akan distabilisasi dengan kadar kapur yang berbeda-beda. Kadar kapur yang akan dipakai adalah 6\%,8\%, 10\%, dan 12\%. Dalam proses pencampuran menggunakan campuran antara tanah asli dan kapur dengan perbandingan berat $5 \mathrm{~kg}$ tanah asli persempel dari berat kering tanah asli itu sendiri, ditambah pencampuran kadar kapur sesuai dengan masing - masing percobaan. Hasil penelitian tersebut dapat dianalisa bahwa Penstabilan tanah untuk perkerasan jalan dengan kapur setelah melalui proses pengujian laboratorium telah layak, dengan menghasilkan Nilai CBR unsoaked tanah asli sebesar 46,48\%, sementara nilai CBR unsoaked tanah dengan campuran 6\% kadar kapur yang dipadatkan kemudian langsung di uji nilai CBR-nya adalah sebesar $48,41 \%$. lebih efektif dibandingkan dengan pencampuran tanah asli plus kadar kapur $8 \%, 10 \%$, dan $12 \%$.
\end{abstract}

Keywords : Stabilisasi, Tanah, Kapur, dan uji CBR (California Bearing Ratio)

\section{Pendahuluan}

Dengan Semakin meningkatnya usaha, pembangunan, dan pertambahan penduduk. maka pembangunan jalan pun harus di tingkatkan. Jalan raya sebagai salah satu sarana lalu lintas menjadi kebutuhan yang penting. Oleh karena itu, apabila jalan raya itu mengalami kerusakan maka akan menghambat pertumbuhan di wilayah tersebut.

Stabilisasi tanah didefinisikan sebagai perbaikan material jalan lokal yang ada, dengan cara stabilisasi mekanis atau dengan cara menambahkan suatu bahan tambah (additive) ke dalam tanah.

Penelitian tentang penambahan kapur sendiri sudah pernah di lakukan oleh Teodore Ignatius Minaroy (2011) . penelitian ini ingin mencoba melihat potansi Pencampuran kapur untuk stabilisasi tanah Depok. Dari penelitian ini didapatkan hasil - hasil sebagai berikut : Nilai kadar kapur yang paling efektif untuk stabilisasi tanah residual Depok adalah 10\% dari berat keringnya. Pencampuran tanah dengan kapur akan menghasilkan campuran yang cenderung berbutir. Tanah dengan campuran kapur akan cenderung bersifat nonkohesif, sementara nilai CBR unsoaked-nya lebih tinggi jika di bandingkan tanah asli tanpa campuran kapur. Nilai CBR unsoaked tanah asli sebesar 50,71\%, sementara nilai CBR unsoaked tanah dengan campuran kadar kapur $10 \%$ yang dipadatkan lalu diperam selama satu hari sebesar 78,27\%. 


\section{Tujuan}

Tujuan yang ingin dicapai pada penelitian ini adalah untuk mengetahui karakteristik pemadatan tanah sebelum dicampur dengan kapur, mengetahui pengaruh penambahan kapur pada tanah terhadap kekuatan daya dukung tanah, mengetahui kelayakan tanah yang distabilkan dengan kapur sebagai lapisan pondasi bawa pada suatu perkerasan jalan, dan untuk Mengetahui Persentasi Penambahan kapur yang paling efektif untuk meningkatkan daya dukung tanah.

\section{Metode}

Jenis penelitian yang digunakan oleh penulis adalah penelitian kuantitaf. Penelitian kuantitatif adalah penelitian yang menggunakan hitungan, statistik, dan tabel dengan kaidah-kaidah tertentu. Pada penelitian ini pengumpulan data dilakukan pada ruas Jalan Distrik Mariat Pantai Kabupatan Sorong. Bahan yang digunakan dalam penelitian di laboratorium adalah : Tanah lempung yang diambil sampel tanahnya dari daerah mariat pantai kabupaten sorong Kapur mentah atau kapur tohor yang diambil sempelnya dari daerah wayer kabupaten sorong selatan. Alat yang digunakan dalam penelitian di laboratorium adalah : Tabung silinder (mold) berdiameter $15 \mathrm{~cm}$ (6 inch) dengan volume $2837 \mathrm{~cm}^{3}\left(1 / 10 \mathrm{ft}^{3}\right)$ yang dilengkapi dengan alas dan tabung tambahan di bagian atas yang disebut collar, Penumbuk (hammer) berat 10 lbs (sekitar $4.5 \mathrm{~kg}$ ), Cawan alumunium, Timbangan, Saringan atau ayakan lengkap, Oven, Desikator, Piknometer $100 \mathrm{ml}$, Hidrometer, Gelas ukur, Casagrande, Mesin penekan (compression machine), Pengukur waktu (jam tangan, stop watch), Alat tulis, Laptop dan alat - alat lainnya

\section{Teknik pengumpulan data}

Dalam teknik pengumpulan data, ada dua jenis yaitu pengumpulan Data Primer dan sekunder. Data primer adalah data yang diperoleh dengan pengumpulan langsung di lapangan yang menjadi objek penelitian. Data
Sekunder adalah data yang didapat dari referensi-referensi yang berkaitan dengan topik yang sedang dibahas baik melalui bukubuku maupun media elektronik seperti website. Data Sekunder Meliputi: Peta jaringan Trayek dan gambaran umum wilayah penelitian. pengumpulan data sekunder : studi pustaka Pengumpulan data-data dari hasil penyelidikan, penelitian, pedoman, bahan acuan, maupun standar yang ada dan media elektronik seperti website.

Studi Penelitian ini merupakan metode penelitian yang dilakukan di laboratorium. Penelitian yang menggunakan jenis material tanah lempung mariat. Contoh Tanah ini akan dicampur kapur untuk kemudian diketahui karakteristik daya dukungnya berdasarkan uji CBR. Pengujian CBR akan di lakukan di Laboratorium Mekanika Tanah Teknik Sipil Universitas Muhammadiyah Sorong, penelitian Karakteristik penambahan pada kapur pada tanah lempung ini akan dilakukan pada kondisi $6 \%, 8 \%, 10 \%, \& 12 \%$. Penambahan kapur dari berat kering tanah untuk mencari efek signifikansi dari penambahan kapur.

Tabel.1. Jumlah Sampel Penelitian

\begin{tabular}{llcc}
\hline No. & Sampel & $\begin{array}{c}\text { Jumlah } \\
\text { Sampel }\end{array}$ & $\begin{array}{c}\text { Keterangan } \\
\text { Penambahan } \\
\text { Kapur }\end{array}$ \\
\hline 1. & Tanah (T) & 3 & - \\
2. & $\begin{array}{l}\text { Tanah + } \\
\text { Kapur } \\
\text { (TK 1) }\end{array}$ & 3 & $6 \%$ \\
3. & $\begin{array}{l}\text { Tanah + } \\
\text { Kapur } \\
\text { (TK 2) } \\
\text { Tanah + } \\
\text { Kapur } \\
\text { (TK 3) }\end{array}$ & $8 \%$ \\
Tanah + \\
Kapur \\
(TK 4)
\end{tabular}




\section{Jurnal Rancang Bangun 2(2)1-14 2017}

\section{Tahapan Penelitian}

Tahapan dari penelitian ini dengan tahapan persiapan tanah, uji indeks properti tanah yang diperlukan, pemadatan tanah (Modified proctor test), dan uji CBR. Tanah ini diambil sebagai sample dari lokasi di Mariat, sedangkan material kapur lokal di ambil dari daerah Teminabuan. Tanah yang diambil disiapkan agar tercapai kondisi kering udara agar dapat dilakukan penyaringan serta pengaturan kadar air dan pemeraman untuk dilakukan pemadatan, di mana pemadatan digunakan metode proctor yang dimodifikasi agar tercapai nilai CBR yang tinggi. Sedangkan untuk sampel campuran tanah dengan kapur dilakukan dengan kondisi tanah kering udara dengan kadar air diketahui, hal ini agar kapur dapat tercampur dengan merata atau homogen. Dari kedua pencampuran tersebut maka persentase kadar air secara analitis akan berubah menjadi lebih kecil karena kapur dalam keadaan kering murni sehingga harus dicari persentase kadar air pencampuran, yang nantinya akan digunakan sebagai perhitungan kadar air desain yang diinginkan. Untuk setiap sampel dengan persentase pencampuran tanah dengan kapur akan dicari kurva pemadatannya, di mana sama halnya seperti perlakuan terhadap sampel tanah.
Setelah mendapatkan campuran antara tanah plus kapur yang di inginkan, maka penguji melakukan uji atterberg limit dengan cara percobaan yang di inginkan. Dari uji atterberg limit didapat nilai batas cair sebesar 55,11 dan indeks plastisitas sebesar 22,54. Nilai indeks plastisitas didapat dari perhitungan LL - PL, dengan LL adalah batas cair tanah dan PL adalah batas plastis tanah. Setelah melakukan pengujian pada tanah asli, penguji langsung melakukan pengujian dengan 4 contoh tanah lainnya yang telah dicampur dengan kapur, masing-masing dengan kadar kapur sebesar 6\%,8\%,10\%, dan $12 \%$. Persentase kadar kapur ini diperoleh dari berat kering tanah. Untuk setiap sampel uji, disiapkan sebanyak 500 gram tanah lolos saringan no 40 ASTM dengan kondisi kering oven.

Tanah dicampur dengan kapur, diaduk secara merata sampai telah kelihatan homogen menjadi satu kesatuan campuran tanah plus kapur. Masing-masing contoh tanah plus kapur tersebut kembali diuji batas-batas atterbergnya. Setelah mendapatkan nilai LL, PL, dan PI untuk masing-masing contoh, nilai-nilai tersebut diplot ke dalam grafik untuk mengetahui bagaimana perilaku tanah jika dicampur dengan kapur.

\section{Hasil Penelitian}

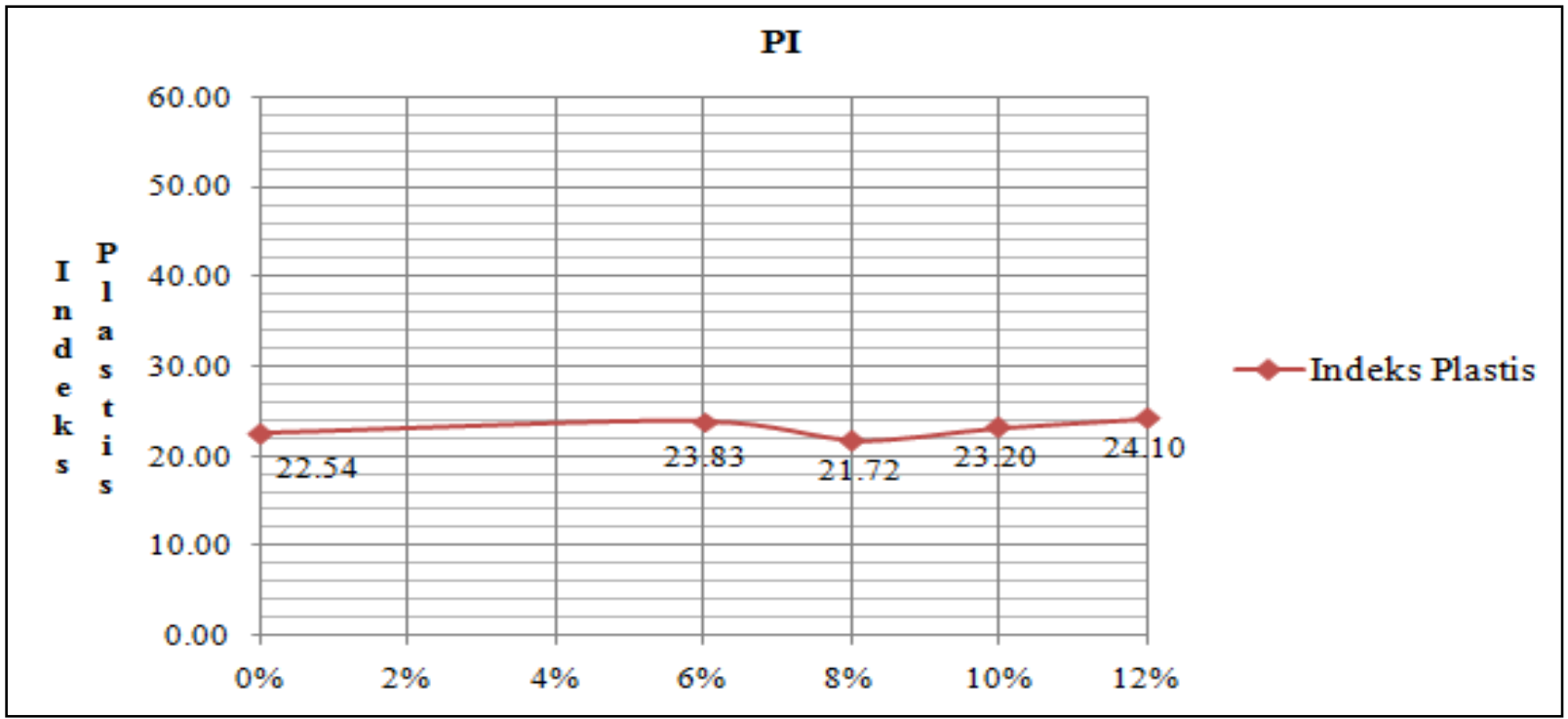

Gambar 1. Indeks Plastisitas Terhadap Persentase Kadar Kapur 


\section{Jurnal Rancang Bangun 2(2)1-14 2017}

Untuk selanjutnya dapat kita lihat dari gambar.1 grafik ( indeks plastis ) di atas terlihat bahwa tren nilai indeks plastisitas tanah akan menurun seiring bertambahnya kadar kapur. Hal ini menunjukkan bahwa tanah menjadi lebih berbutir, dan potensi pengembangannya (swelling) menjadi berkurang. Dengan begitu, penambahan kapur akan meningkatkan mutu tanah dari segi kekuatannya. Sifat-sifat ini sangat cocok jika diterapkan untuk perkerasan jalan.

Dari grafik tersebut juga terlihat bahwa nilai indeks plastisitas tanah dengan kadar kapur $6 \%$ lah yang paling mendekati trend line, sehingga kadar kapur $6 \%$ lah yang paling efektif. Untuk lebih jelasnya berikut metode perhitungan pengujian atterbeg limit :

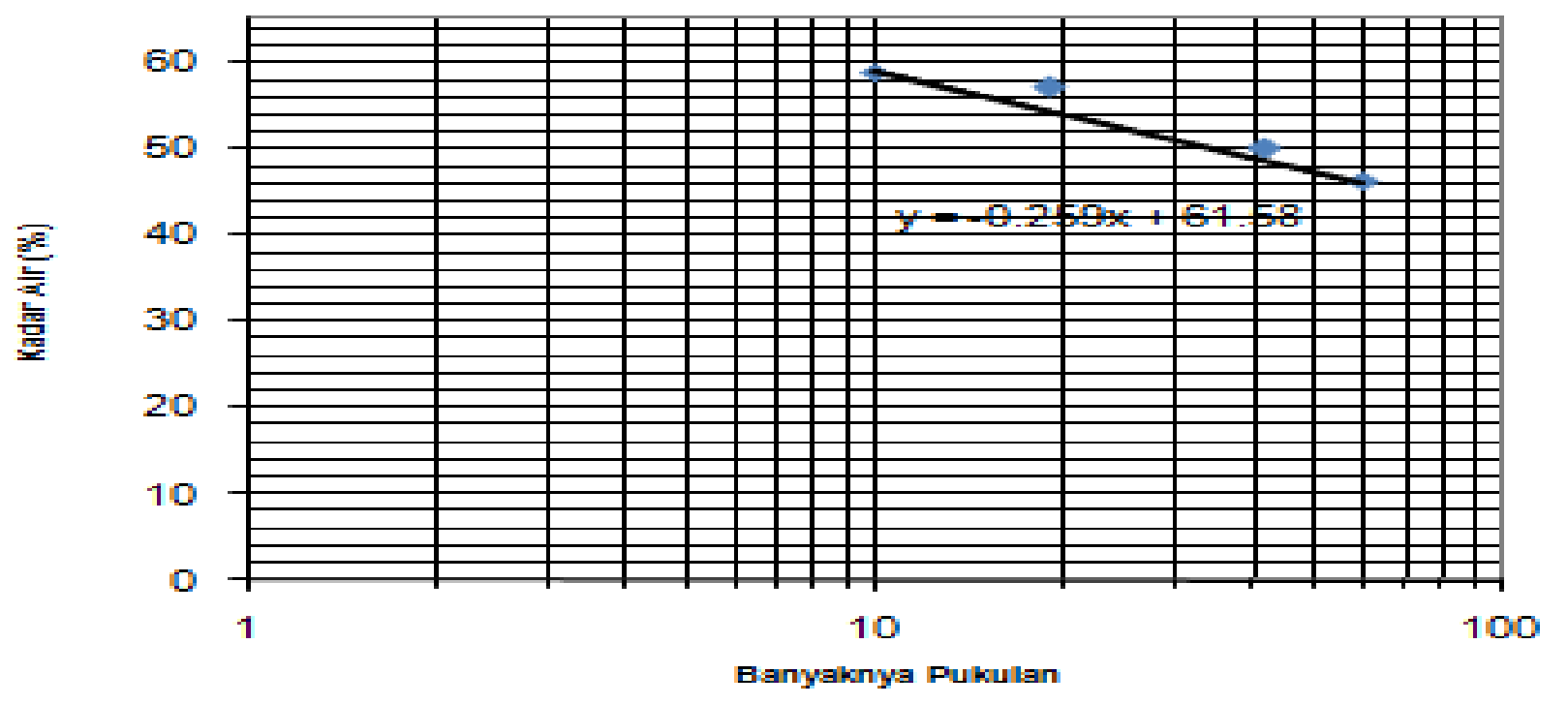

Gambar 2. Kurva Aliran Untuk Penentuan Batas Cair Tanah Asli

\section{Metode Pengujian Batas-Batas Atterberg}

Analisa perhitunngan :

1). Rumus mencari nilai kadar air $(\omega)$ dan penyelesainnya :

$$
\begin{aligned}
\begin{array}{l}
\omega=\frac{W w}{W d} \\
\mathrm{x}
\end{array} & 100 \\
= & \frac{1,95}{4,21} \times 100 \\
& =46,32
\end{aligned}
$$

Dimana :

$$
\begin{aligned}
\mathrm{Ww} & =\text { Berat air } \\
\mathrm{Ww} & =\mathrm{W} 1-\mathrm{W} 2 \\
& =20,48-18,53 \\
& =1,95 \\
\mathrm{Wd} & =\text { Berat tanah kering } \\
\mathrm{Wd} & =\mathrm{W} 2-\mathrm{W} 3 \\
& =18,53-14,32
\end{aligned}
$$

$$
=4,21
$$

$\mathrm{W} 1=$ Berat tanah basah + Container

$\mathrm{W} 2=$ Berat tanah kering + Container

W3 $=$ Berat Container

2). Rumus mencari batas cair (WL) dan penyelesaiannya

$$
\begin{aligned}
\mathrm{WL} & =\mathrm{WN} \times\left(\frac{\mathrm{N}}{25}\right) \\
& =-0,259 \operatorname{Ln}(25)+61,58 \\
& =55,11 \\
\mathrm{WL} & =\text { Batas cair } \\
\mathrm{WN} & =\text { Kadar air pada pukulan } \mathrm{N} \\
\mathrm{N} & =\text { Pukulan yang mendekati }
\end{aligned}
$$

pukulan ke-25

Untuk perhitungan di bawah dapat dilihat pada tabel 2. berikut ini : 
Tabel.2. Batas - batas Atterberg Tanah Asli Mariat Pantai

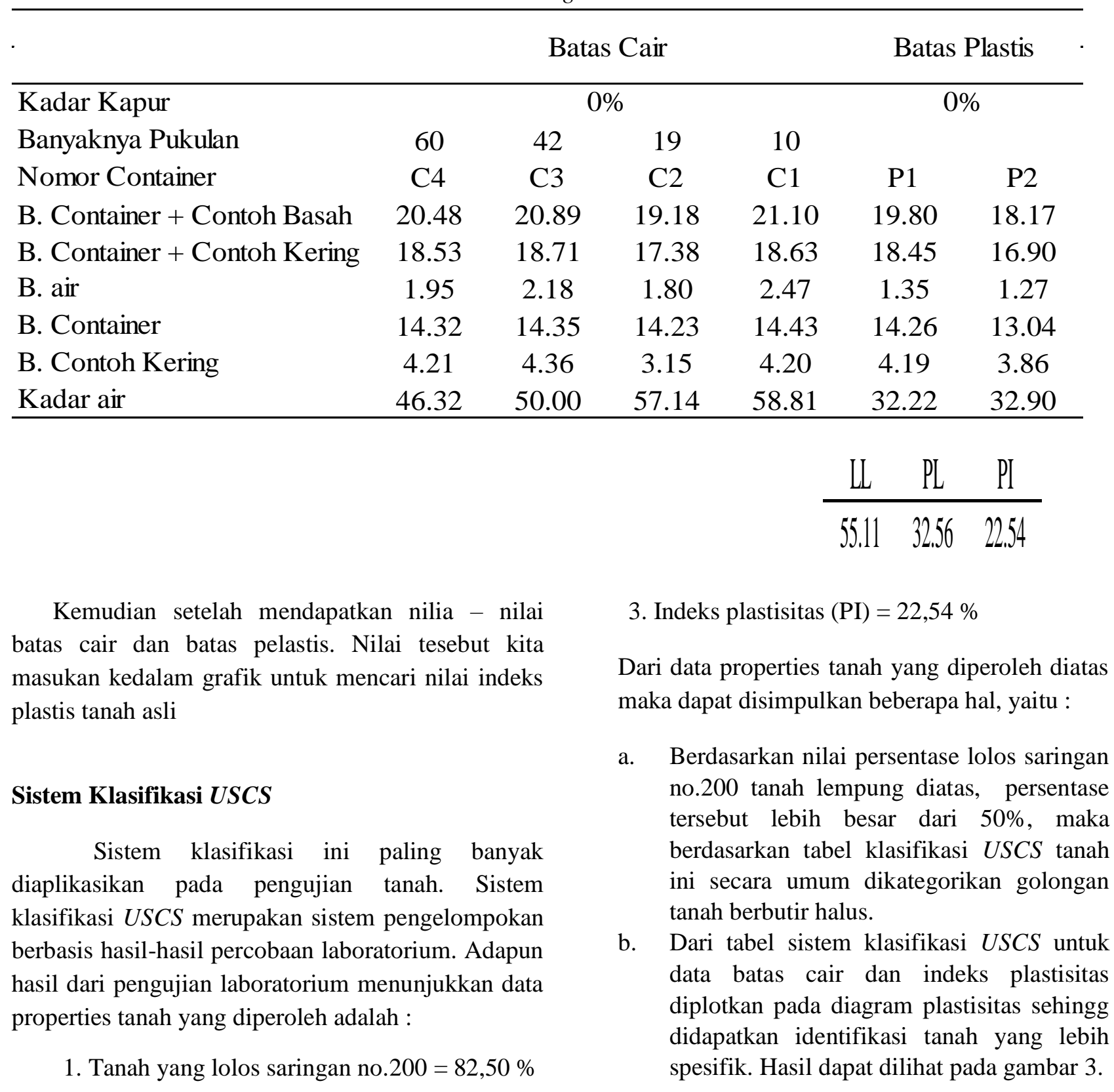

2. Batas Cair $(\mathrm{LL})=55,60 \%$ 


\section{Jurnal Rancang Bangun 2(2)1-14 2017}

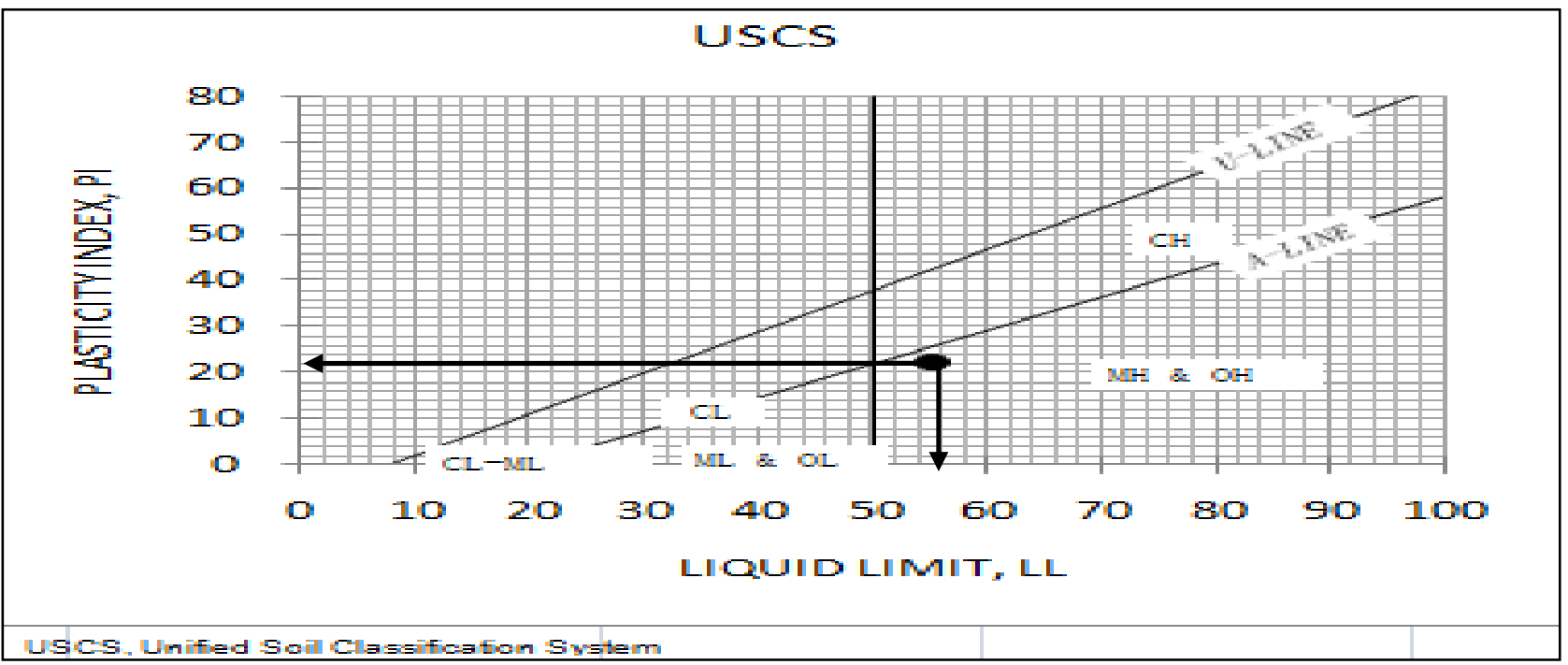

Gambar 3. Grafik hubungan antara plastic index dan liquid limit tanah asli mariat pantai menurut pendapat

\section{Sistem Klasifikasi AASHTO}

USCS

Berdasarkan pada tabel klasifikasi tanah AASHTO dan properties tanah, dimana persentase lolos saringan no 200 lebih dari 35\%, sehingga dapat disimpulkan secara umum tanah masuk dalam kelompok lanau-lempung. Dengan diketahuinya nilai batas cair (LL) lebih besar dari $41 \%$, dan nilai indeks plastisitas (PI) lebih besar dari $11 \%$ tetapi lebih besar dari pada nilai batas cair (LL) dikurangi 30, maka tanah termasuk golongan A-7-5.

Untuk mendapatkan pengelompokkan yang lebih detail maka dapat dilihat pada gambar 15 .

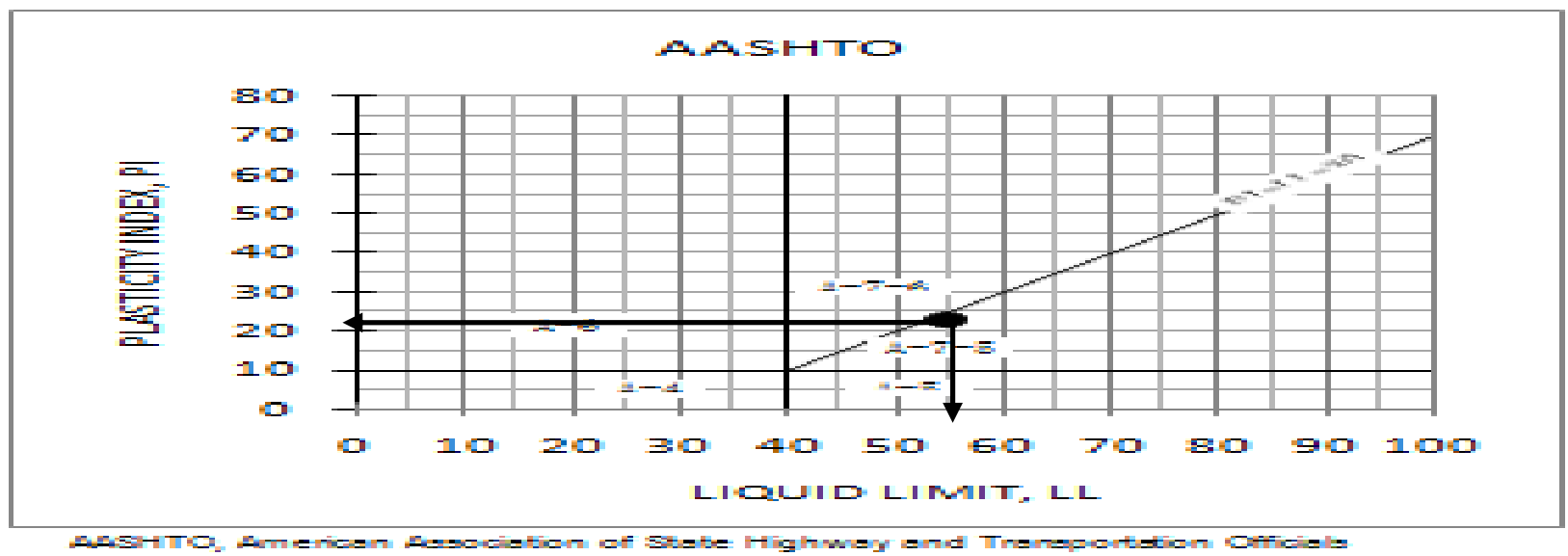

Gambar 4. Grafik hubungan antara plastic index dan liquid limit tanah asli mariat pantai menurut pendapat AASHTO

\section{Metode Pengujian Spesific Gravity}

Berdasarkan gambar diatas maka tanah lempung yang berasal dari derah mariat pantai dapat dikategorikan kedalam kelompok tanah berlempung A-7-5
Analisa perhitunngan:

1). Rumus mencari berat jenis Spesific Gravity (GS) dan Penyelesaiannya:

$$
\mathrm{Gs}=\frac{W t}{(W 5+W 2-W 3)}
$$




$$
\begin{aligned}
& =\frac{10.00}{(101.06+87.04-184.03)} \\
& =2.46 \\
\text { Gs } & =\frac{a W t}{(W 5+W 2-W 3)} \\
& =\frac{(0.99598 \times 10.00)}{(101.06+87.04-184.03)} \\
& =2.45
\end{aligned}
$$

Dimana :

$\mathrm{W} 2=$ Berat piknometer dan air suling

W3 = Berat piknometer, tanah, dan air suling

$\mathrm{Wt}=$ Berat tanah

\begin{tabular}{|c|c|c|c|c|c|}
\hline \multicolumn{6}{|c|}{ Pemeriksaan Berat Jenis } \\
\hline \multirow{2}{*}{$\begin{array}{l}\text { Kadar Kapur } \\
\text { Jenis Tanah } \\
\text { Nomor Piknometer }\end{array}$} & & \multicolumn{2}{|c|}{$\begin{array}{c}\mathrm{O} \% \\
\text { Lempung }\end{array}$} & \multicolumn{2}{|c|}{$\begin{array}{c}\text { O\% } \\
\text { Lempung }\end{array}$} \\
\hline & & 1 & 2 & 3 & 4 \\
\hline Berat Piknometer & W1 & 77.04 & 75.12 & 76.89 & 77.47 \\
\hline Berat Piknometer + Contoh & W2 & 87.04 & 85.12 & 86.89 & 87.47 \\
\hline Berat Tanah + Kapur (Wt) & W2 - W1 & 10.00 & 10.00 & 10.00 & 10.00 \\
\hline Berat Piknometer + Air + Tanah & W3 & 184.03 & 183.44 & 183.18 & 183.27 \\
\hline Berat Piknometer + Air Padat & W4 & 178.10 & 177.32 & 176.98 & 177.49 \\
\hline W5 & $W_{2}-W_{1}+W_{4}$ & 188.10 & 187.32 & 186.98 & 187.49 \\
\hline Isi Tanah & W5 - W3 & 4.07 & 3.88 & 3.80 & 4.22 \\
\hline Berat Jenis & Wt / Isi Tanah & 2.46 & 2.58 & 2.63 & 2.37 \\
\hline $\begin{array}{l}\text { Rata-rata } \\
\text { Keterangan }\end{array}$ & & & 2.5 & & \\
\hline Temperatı 29 ) & & & & & \\
\hline
\end{tabular}

$$
\begin{aligned}
& \mathrm{W} 5=\mathrm{W} 4-\mathrm{W} 1 \\
& \mathrm{~W} 1=\text { Berat piknometer kering dan } \\
& \text { kosong } \\
& \begin{aligned}
\mathrm{W} 4 & =\text { Berat piknometer }+ \text { tanah } \\
\alpha & =\text { Faktor koreksi } \\
\mathrm{T} & =\text { Temperatur } / \text { suhu sesuai }
\end{aligned} \\
& \text { dengan suhu kamar }
\end{aligned}
$$

Untuk perhitungan di atas dapat dilihat pada tabel 3. berikut ini :

Tabel 3. Berat jenis Tanah Asli Mariat Pantai

\section{Metode Pengujian Hidrometer \& Analisa Saringan}

Analisa perhitunngan :

1). Rumus pengujian Hidrometer dan penyelesaiannya :

$\mathrm{Rcp}=\mathrm{R}+$ Temperature Correction + Zero Corection

$$
\begin{aligned}
& =46+0+0 \\
& =46 \\
\mathrm{Rcl} & =\mathrm{R}+\text { Minescus Correction } \\
& =46+1 \\
& =4
\end{aligned}
$$

Dimana :

Rcp = Hasil pembacaan alat ukur hidrometer yang sudah di koreksi

$\mathrm{R}=$ Hasil pembacaan hidrometer

Untuk persentasi butiran-butiran halus, dapat dihitung dengan menggunakan rumus :

$$
\begin{aligned}
\% \text { Butiran halus } & =\frac{\alpha \cdot R c p}{w s} \times 100 \% \\
& =\frac{1.04 \times 46}{60} \times 100 \% \\
& =79.6
\end{aligned}
$$

Dimana :

Ws $=$ Berat kering contoh tanah

$\alpha=$ Koreksi untuk berat jenis dari butiran tanah

$$
\begin{aligned}
\alpha & =\frac{G s \times 1.65}{(G s-1) \times G s} \\
& =\frac{60 \times 1.65}{(60-1) \times 60} \\
& =1.04
\end{aligned}
$$

Rumus untuk mencari garis tengah butir - butir tanah adalah:

$$
\begin{aligned}
\mathrm{D} & =\mathrm{k}\left(\begin{array}{l}
\mathrm{L} \\
\mathrm{t}
\end{array}\right)^{\mathrm{o} .5} \\
& =0.0130\left(\begin{array}{l}
8.6 \\
0.5
\end{array}\right)^{\circ .5} \\
= & 0.054
\end{aligned}
$$

Dimana : 


\section{Jurnal Rancang Bangun 2(2)1-14 2017}

$\mathrm{K}=$ Rasio kekentalan air yang di tentukan dengan menggunakan grafik

$\mathrm{L}=$ Panjang efektif yang ditentukan dengan menggunakan grafik yang di beri pada gambar sesuai dengan harga $\mathrm{R}$ yang bersangkutan $\mathrm{t}=$ Waktu pembacaan

Untuk perhitungan di atas dapat dilihat pada tabel 4. berikut ini :

Tabel 4. Pengujian hidrometer tanah asli mariat pantai

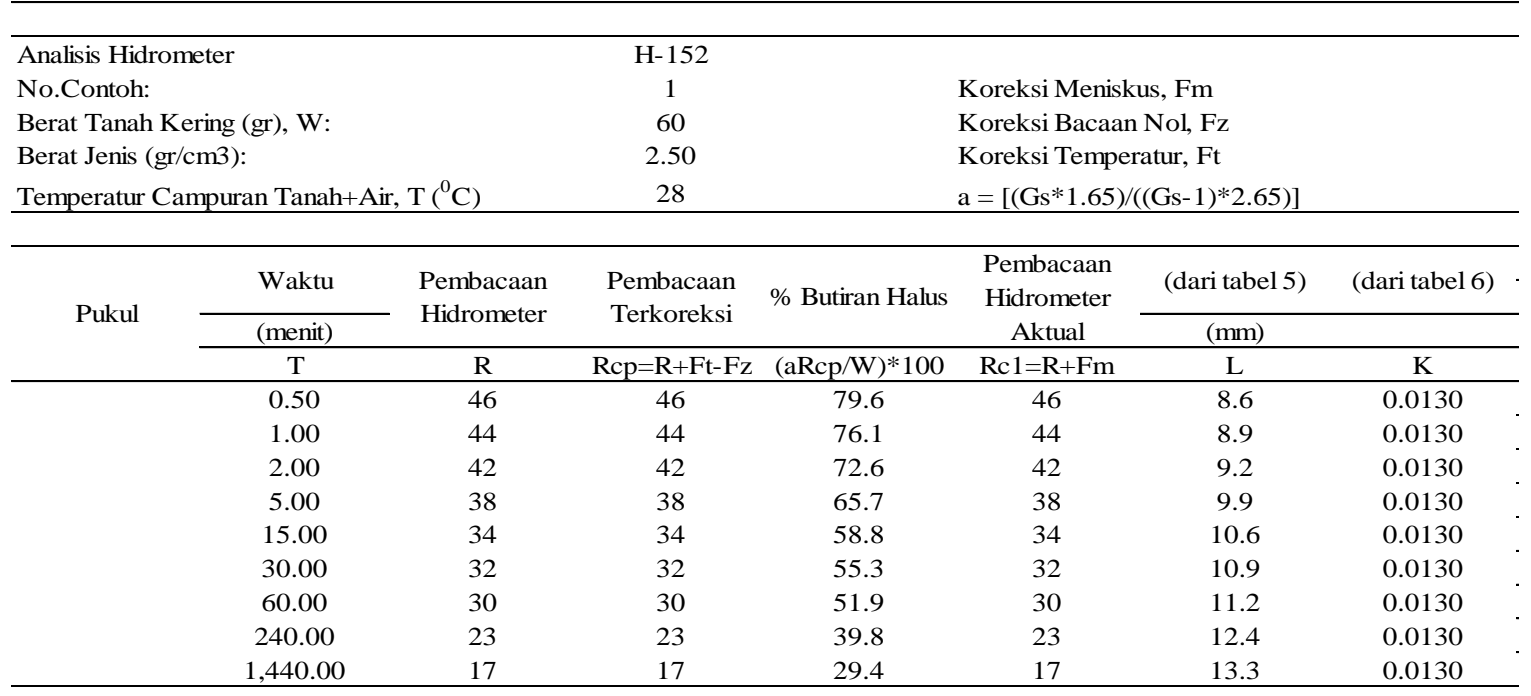

2 ). Rumus pengujian Analisa saringan dan

penyelesaiannya :

Dalam melakukan percobaan akan di peroleh berat tanah kering, selain itu diperoleh juga berat tanah yang tertahan serta berat kumulatifnya. Dari data tersebut maka dapat dipergunakan rumus :

$\%$ Butiran halus $=\frac{\text { Berat komulatif }}{\text { Berat }} \times 100 \%$

$$
=\frac{1.73}{60} \times 100 \%
$$$$
=2.88
$$

$\%$ Lolos

$=100 \%-$ Persentase

tertahan

$$
\begin{aligned}
& =100 \%-2.88 \\
& =97,12 \%
\end{aligned}
$$

Untuk lebih jelasnya dapat dilihat pada tabel 5. berikut ini: 


\section{Jurnal Rancang Bangun 2(2)1-14 2017}

Tabel 5. Pengujian Analisa saringan tanah asli mariat pantai

\begin{tabular}{|c|c|c|c|c|c|c|c|}
\hline Analisis Saringan & & \multicolumn{2}{|c|}{ Saringan } & \multicolumn{3}{|c|}{ Tertahan } & Lolos \\
\hline \multirow[t]{11}{*}{$\underline{\text { Berat Total }}$} & 11.44 gram & Nomor & $\begin{array}{l}\varnothing \text { Lubang } \\
(\mathrm{mm})\end{array}$ & Berat (gr) & $\%$ & $\begin{array}{c}\% \\
\text { Kumulatif }\end{array}$ & $\%$ \\
\hline & & $\# 4$ & 4.75 & - & - & - & 100.00 \\
\hline & & \# 10 & 2.00 & - & - & - & 100.00 \\
\hline & & \# 18 & 0.850 & 1.73 & 2.88 & 2.88 & 97.12 \\
\hline & & \# 40 & 0.425 & 2.94 & 4.90 & 7.78 & 92.22 \\
\hline & & \# 100 & 0.149 & 2.63 & 4.38 & 12.17 & 87.83 \\
\hline & & \# 200 & 0.075 & 3.20 & 5.33 & 17.50 & 82.50 \\
\hline & & PAN & & 0.80 & & & \\
\hline & & \multicolumn{2}{|c|}{ Berat Total } & 11.30 & & & \\
\hline & & \multicolumn{6}{|c|}{ Tanah yang hilang selama pengujian analisis saringan harus kurang dari $2 \%$} \\
\hline & & 1.22 & $<$ & 2.00 & (Memenu & hi Syarat) & \\
\hline
\end{tabular}

\section{Compaction}

Uji Compaction menggunakan sampel tanah asli, uji lolos saringan nomor 4 ASTM. Uji compaction yang dilakukan adalah dengan metode Modified Proctor dengan mold berdiameter besar. Hal ini dilakukan agar ada kesesuaian dengan uji California Bearing Ratio yang akan di lakukan kemudian.

Penulis melakukan pemadatan sebanyak tiga titik, dengan kadar air yang di targetkan masingmasing adalah 5\%, 16\% dan 25\%. Dari ketiga titik tersebut akan didapatkan sebuah kurva pemadatan. Kurva pemadatan dibuat dengan cara menghubungkan nilai kadar air dan berat isi kering dari titik-titik tersebut. Untuk lebih jelasnya berikut metode perhitungan pengujian Compaction :

\section{Metode pengujian compaction}

Analisa perhitunngan:

1). Rumus pengujian kompaksi dan penyelesaiannya :

Rumu mencari kadar air $(\omega)$ :

$$
\begin{gathered}
\omega=\frac{W 3}{W 5} \times 100 \% \\
=\frac{0.26}{5.66} \times 100 \% \\
=5 \%
\end{gathered}
$$

Dimana :

$$
\begin{aligned}
& \text { W3 = Berat Air } \\
& \text { W5 }=\text { W1 }- \text { W2 }
\end{aligned}
$$

$=20.31-20.05$

$=0.26$

W5 $=$ Berat Tanah Kering

$$
\begin{aligned}
\mathrm{W} 5 & =\mathrm{W} 2-\mathrm{W} 4 \\
& =20.05-14.39 \\
& =5.66
\end{aligned}
$$

$\mathrm{W} 1=$ Berat Tanah Basah + Contaner

$\mathrm{W} 2=$ Berat Tanah Kering + Contaner

W4 $=$ Berat Contaner

2). Rumus mencari berat volume basah :

$$
\begin{aligned}
\rho \mathrm{w} & =\mathrm{Wwet} / \mathrm{V} \\
& =3391 / 2121 \\
& =1.60
\end{aligned}
$$

Dimana :

Wwet $=$ Berat tanah basah

$$
\begin{aligned}
\text { Wwet } & =\mathrm{W} 1-\mathrm{W} 4 \\
& =9058-5667 \\
& =3391
\end{aligned}
$$

$\mathrm{V}=$ Volume mold

$\mathrm{W} 1=$ Berat mold

$\mathrm{W} 2=$ Berat tanah basah + mold

$3)$. Rumus mencari berat kering ( $\rho d)$ :

$$
\begin{aligned}
\rho d & =\frac{\rho w}{100+w} \times 100 \% \\
& =\frac{1.60}{100+5} \times 100 \% \\
& =1.53
\end{aligned}
$$




\section{Jurnal Rancang Bangun 2(2)1-14 2017}

Untuk perhitungan di atas dapat dilihat pada tabel 6. berikut ini :

Tabel 6. Data Pemadatan Tanah Asli

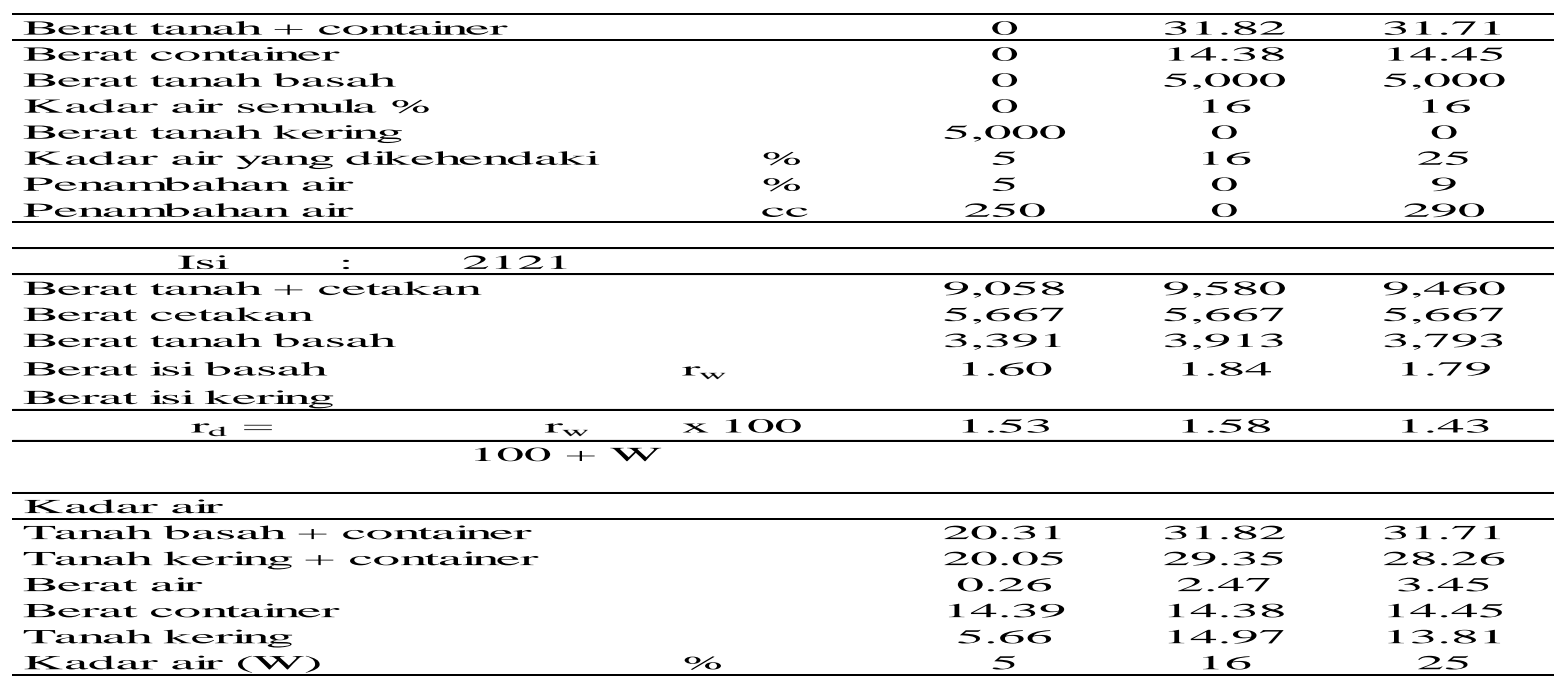

Data Grafik

$\begin{array}{rrrr}\mathrm{rd} & 1.53 & 1.58 & 1.43 \\ \mathrm{~W} & 5 & 6 & 25\end{array}$

Zero Air Void Line

\begin{tabular}{|c|c|c|}
\hline $\mathrm{rd}=$ & $\frac{\text { G.rw }}{100+G . W} \times 100$ & 1.95 \\
\hline rd & berat isi kering & 1.60 \\
\hline Gs & berat jenis tanah & 2.62 \\
\hline rw & berat isi air & 1 \\
\hline $\mathrm{W}$ & kadar air & 13 \\
\hline
\end{tabular}

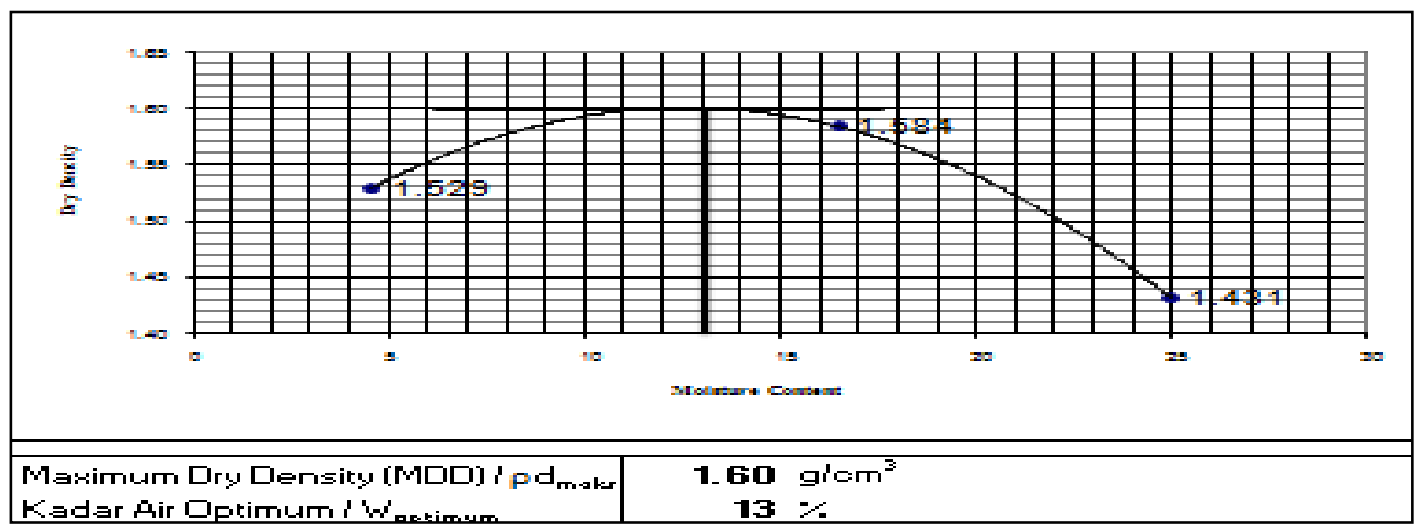

Gambar 5. Kurva Pemadatan Tanah Asli 


\section{Jurnal Rancang Bangun 2(2)1-14 2017}

Dari uji Compaction, yang telah di lakukan seperti gambar di atas didapat berat jenis kering maksimum sebesar $1,60 \%$ pada kadar air optimum $13 \%$.

\section{California Bearing Ratio}

metode perhitungan-nya :

1). Rumus pengujian CBR Laboratorium dan penyelesaiannya :

Kadar air :

$$
\begin{aligned}
W & =\frac{W w}{W d} \times 100 \% \\
& =\frac{2.87}{21.35} \times 100 \% \\
& =13 \%
\end{aligned}
$$

Dimana :

$$
\begin{aligned}
& W w=\text { Berat air } \\
& W d=\text { Berat Tanah Kering }
\end{aligned}
$$

Untuk metode pencampuran tanah asli mariat pantai dengan kadar air optimum $13 \%$ yang di dapat dari hasil pengujian compection,

kemudian hasil tersebut di gunakan untuk pengujian CBR yang maksimal. Selanjutnya digunakan rumus untuk mencari nilai kadar air optimum $13 \%$ dari berat kering tanah 5000 $\mathrm{gr} / \mathrm{cm}^{3}$ untuk persiapan pengujian CBR sebagai berikut.

a). Kadar air $13 \%$ yang ingin di capai untuk pengujian CBR tanah asli maupun campuran :

$$
\begin{aligned}
& 13 \%=\frac{13 \%}{x}=13 \% \times 5000 \mathrm{gr} / \mathrm{cm}^{3}= \\
& 650 \mathrm{gr} / \mathrm{cm}^{3}=650 \mathrm{ml}
\end{aligned}
$$

Berat Isi :

- $\quad$ Berat isi basah $\rightarrow \gamma$ wet $=\frac{\text { Wwet }}{\text { Vmould }}$

$$
=\frac{4150}{2124}
$$

$$
\begin{aligned}
& =1.95 \\
\text { - Berat isi kering } \rightarrow \gamma \mathrm{d} & =\frac{\gamma w e t}{100+\mathrm{w}} \times 100 \% \\
& =\frac{1.95}{(100+13)} \times 100 \% \\
& =1.73
\end{aligned}
$$

- Nilai-nilai penurunan dan beban diplotkan ke dalam grafik sehingga didapatkan persamaan regresinya, kemudian nilai $\mathrm{x}(0,1 \quad \& \quad 0,2)$ dimasukkan ke dalam persamaan regresinya sehingga didapatkan nilai beban (lbs).

- Dari nilai beban dibagi dengan 3000 (u/penurunan 1 inch) \& 4500 (u/penurunan 2 inch) didapatkan nilai CBR-nya, lalu nilai CBR ( 1 inch +2 inch)/2 untuk dapat nilai CBR ratarata.

Dengan metode perhitungan CBR sebagai berikut:

1). $\mathrm{CBR}=\frac{P T}{P S} \times 100 \%$

$$
\begin{gathered}
=\frac{1370}{3000} \times 100 \% \\
=45,67 \%
\end{gathered}
$$

Keteragan :

$$
\begin{aligned}
& \mathrm{PT}=\text { Beban percobaan (test load) } \\
& \mathrm{PS}=\text { Beban standar (standar load) }
\end{aligned}
$$

Dengan beban (load) didapat hasil pembacaan dial penetrasi yang kemudian di korelasikan dengan grafik calibration proving ring. Serta:

Test unit load $(\mathrm{psi})=$ tegangan $(\sigma)$

2). $\sigma=\frac{P}{A}=\frac{M(L R C)}{A}$

$$
=\frac{50(27.40)}{3 \times 1000}=\frac{1370}{3000}
$$

Keteragan :

$$
\begin{aligned}
& \mathrm{A}=\mathrm{Luas} \text { piston } \\
& \mathrm{P}=\mathrm{M}, \mathrm{M}=\text { dial reading } \\
& \mathrm{LRC}=\text { faktor kalibrasi }
\end{aligned}
$$




\section{Jurnal Rancang Bangun 2(2)1-14 2017}

\section{UJI CBR LAB. TANAH ASLI \& CBR VARIASI PENCAMPURAN KADAR KAPUR $6 \%, 8 \%, 10 \%, 12 \%$ TANPARENDAMAN}

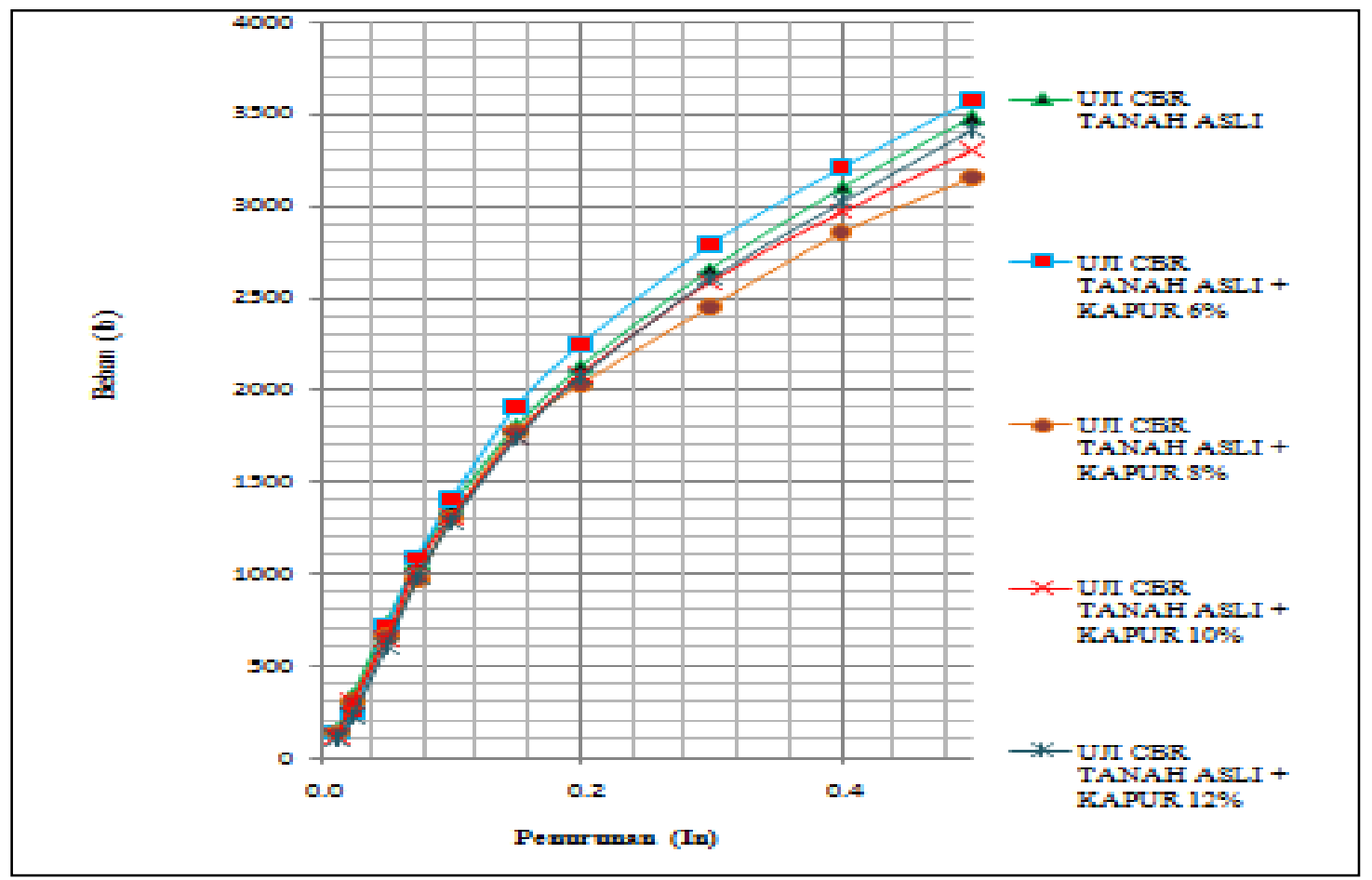

Gambar 6. Nilai CBR Tanah Asli Terhadap Penambahan kadar

Kapur Untuk Penetrasi Pembebanan

Dari hasil yang diperoleh seteleh pengujian CBR untuk penetrasi pembeban pada gambar.19. diatas bahwa telihat nilai efektifitas tanah asli yang di tambahkan dengan kapur $6 \%$, mengalami kenaikan yang sangat signifikan . Di bandingkan dengan penambahan kapur di atas $6 \%$ yang lain.

Setelah ditetapkan pencampuran kadar kapur yang ditargetkan, hal selanjutnya dilakukan pengujian CBR dengan variasi kadar kapur yang berbeda-beda. Ada 5 variasi percobaan dengan setiap satu variasi diuji 3 kali pengujian untuk mencari nilai rata-rata dari setiap pengujian tersebut.

Seperti terlihat pada tabel 7 berikut.

\section{Hasil dan Data Analisa Uji California Bearing Ratio}

Tabel 7. Data uji tanah asli dan tanah asli + kapur dengan masing-masing

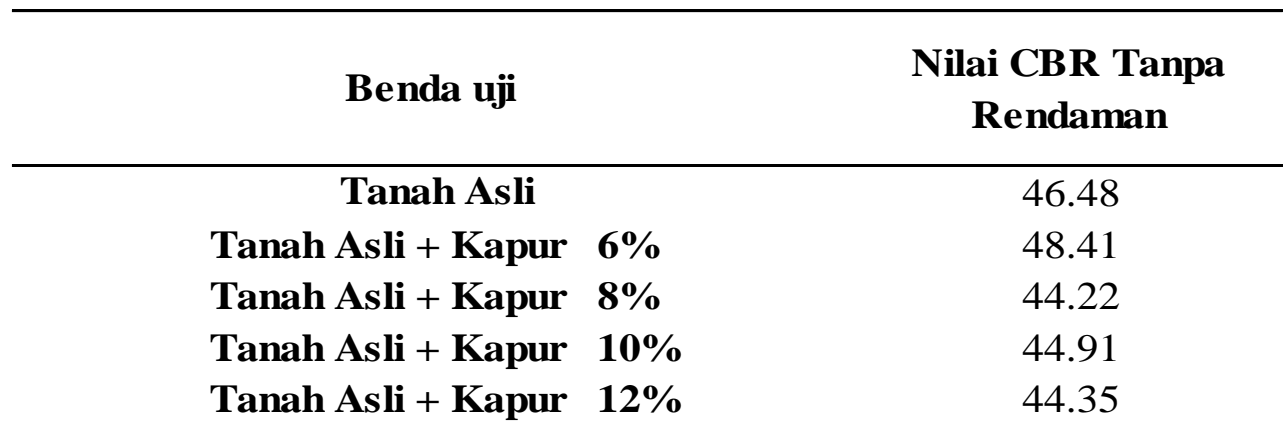


UJI CBR LAB.TANAH ASLI \& CBR VARIASI PENCAMPURAN KADAR KAPUR 6\%, 8\%, 10\%, $12 \%$ TANPA RENDAMAN

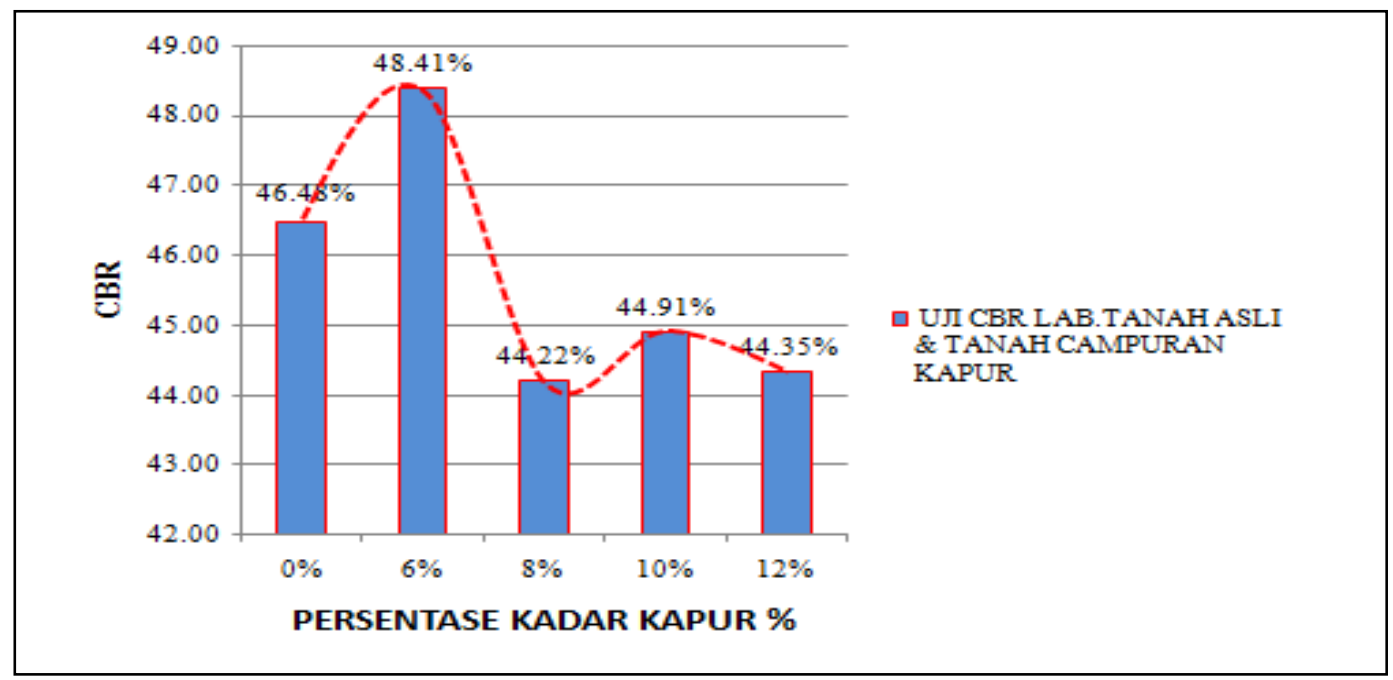

Gambar 7. Pengaruh Nilai CBR Tanah Asli Terhadap Penambahan Kadar Kapur

Terlihat pada gambar 7. di atas, bahwa nilai CBR tanah asli dengan kadar kapur $6 \%$ tanpa rendaman dan pemeraman, nilai CBR-nya mengalami peningkatan lebih tinggi dari nilai CBR tanah asli yaitu sebesar $48,41 \%$. Dari hasil penelitian tersebut dapat dianalisa bahwa pencampuran tanah asli dengan kadar kapur $6 \%$ adalah yang paling efektif. Oleh karena itu perlu di kaji lebih lanjut.

Setelah melakukan pengujian pada tanah asli untuk pengujian CBR, maka selanjutnya akan di lakukan pengujian terhadap tanah yang distabilisasi dengan kapur. Kadar kapur yang akan dipakai adalah 6\%, 8\%, 10\%, dan $12 \%$.

Dalam proses pencampuran penguji menggunakan campuran antara tanah asli dan kapur dengan perbandingan berat $5 \mathrm{~kg}$ tanah asli persempel dari berat kering tanah asli itu sendiri, plus pencampuran kadar kapur sesuai dengan masing - masing percobaan. Sesuai dengan hasil awal yang telah di jabarkan sebelumnya. Kadar air optimum yang dipakai adalah kadar air $13 \%$. Campuran tanah asli dengan kapur tersebut a kan di uji kekuatanya melalui uji California Bearing Ratio (CBR). Sesuai dengan alur penelitin yang telah di jelaskan pada bab sebelumnya, masing-masing sempel akan dipadatkan kemudian di uji langsung alat CBR.
Dari hasil pengujian CBR laboratorium (unsoaked) tanpa pemeraman pada tanah campuran Kapur, dapat dilihat bahwa peningkatkan nilai daya dukung tanah pada pencampuran kadar kapur yang berbeda - beda akan telihat secara signifikan. Setelah ditetapkan pencampuran kadar kapur yang ditargetkan , hal selanjutnya dilakukan pengujian CBR dengan variasi kadar kapur yang berbeda-beda . Ada 5 variasi percobaan dengan setiap satu variasi di uji 3 kali pengujian untuk mencari nilai rata-rata dari setiap pengujian tersebut. nilai CBR tanah asli dengan kadar kapur 6\% tanpa rendaman dan pemeraman, nilai CBR-nya mengalami peningkatan lebih tinggi dari nilai CBR tanah asli yaitu sebesar $48,41 \%$. Dari hasil penelitian tersebut dapat dianalisa bahwa pencampuran tanah asli dengan kadar kapur $6 \%$ adalah yang paling efektif.

\section{Pembahasan}

Sampel uji yang digunakan dalam penelitian adalah sampel uji tanah lempung yang diambil di daerah Mariat Pantai Kabupaten Sorong. Sampel tanah tersebut diambil pada hari rabu dan kamis tanggal 9-10 Juni 2017 yang lalu. Tanah digali mulai dari kedalaman 0,6 meter dari permukaan tanah untuk meminimalisir kotoran seperti akar, tanah humus, sampah dan 
lain-lain. Setelah digali tanah langsung dicacah lalu diayak menggunakan ayakan saringan nomor 4 ASTM, barulah hasil ayakan dimasukan ke dalam karung. Contoh tanah yang didapat merupakan contoh tanah lempung sebanyak $150 \mathrm{~kg}$. tanah yang belum lolos ayakan dipisahkan untuk dijemur selama satu hari, kemudian ditumbuk sampai bisa lolos saringan nomor 4 ASTM. Setelah itu, tanah yang sudah lolos saringan nomor 4 ASTM. dihamparkan di loyang besar di dalam laboratorium untuk mendapatkan kondisi kering udara. Agar kondisi keringnya merata, tanah tersebut diaduk secara berkala. Selanjutnya mempersiapkan contoh tanah untuk pengujian, penguji melakukan beberapa pengujian awal untuk mengetahui data awal tanah asli tersebut, yaitu dengan cara uji atau atterberg limit, uji spesific gravity atau berat jenis,uji Hydrometer, uji compaction, dan uji CBR (California Bearing Ratio).

\section{Kesimpulan}

Dari penelelitian yang dilakukan dapat diperoleh beberapa kesimpulan sebagai berikut : Kondisi karakteristik tanah asli sebelum di campur dengan kapur yaitu kondisi tanah asli bersifat kohesif dan lunak oleh karena itu perlu adanya stabilisasi, Pengaruh tanah asli mariat pantai dengan penabahan kapur Tohor akan menghasilkan campuran yang cenderung berbutir, Tanah dengan campuran kapur bersifat non-kohesif, sementara nilai CBR unsoaked-nya akan lebih tinggi jika dibandingkan dengan tanah asli tanpa campuran kapur, Kemudian Kapur yang digunakan untuk stabilisasi ialah kapur yang lolos saringan No.4. yang berdiameter $4,75 \mathrm{~mm}$, Penstabilan tanah asli untuk perkerasan jalan dengan kapur setelah melalui proses pengujian laboratorium telah layak, dengan menghasilkan Nilai CBR unsoaked tanah asli sebesar 46,48\%. sementara nilai CBR unsoaked tanah dengan campuran $6 \%$ kadar kapur yang dipadatkan kemudian langsung di uji nilai CBR-nya adalah sebesar $48,41 \%$. Campuran tanah asli dan kapur yang paling efektif ialah campuran dengan kadar kapur $6 \%$, kemudian hasil nilai CBR unsoaked pun lebih besar dari pada tanah asli. Hal ini yang membedakan dengan penelitian sebelumnya oleh Teodore Ignatius Minaroy (2011) yang menyatakan bahwa hasil uji yang di dapat untuk pencampuran tanah dengan $10 \%$ kadar kapur, nilai CBR unsoaked justru lebih kecil dari pada nilai CBR dibawah $10 \%$ pada lokasi yang berbeda.

\section{Referensi}

E.Sutarman,Ir.MT. Konsep Dan Aplikasi Mekanika Tanah. yogyakarta: Penerbit Andi

Hartdiyatmo, H.C. 2002. Mekanika Tanah 1. Yogyakarta: Gadjah Mada University Press.

Hartdiyatmo, H.C. 2010. Stabilisasi Tanah Untuk Perkerasan Jalan. Yogyakarta: Gadjah Mada University Press.

Hartdiyatmo, H.C. 2011. Perancangan perkerasan jalan \& penyelidikan tanah. Yogyakarta: Gadjah Mada University Press.

SNI Revisi dari 03- 1743 - 1989 ke 06-17422008 Metode Pengujian Kepadatan Berat Untuk Tanah

SNI Revisi dari 03- 1744 - 1989 ke 07-17442012 Metode Pengujian CBR Laboratorium

SNI Revisi dari 03- 3437 - 1994 Tata Cara Pembuatan Rencana Stabilisasi Tanah Dengan Kapur Untuk Jalan

Teodore Ignatius Minaroy, (2011). Stabilisasi Tanah Residual Depok dengan Kapur 